Supporting Information

\title{
Electrochemically Stable, High Transference Number Lithium Bis(malonato)borate Polymer Solution Electrolytes
}

Beth L. Dewing, † Nicholas G. Bible, , † Christopher J. Ellison,, , and Mahesh K. Mahanthappa,$\dagger$

$\dagger$ Department of Chemistry, University of Minnesota, 207 Pleasant St. E.S., Minneapolis, MN 55455

$\S$ Department of Chemical Engineering \& Materials Science, University of Minnesota 421 Washington

Ave. S.E., Minneapolis, MN 55455

* maheshkm@umn.edu; ; +1 (612) 625-4599

Table of Contents $\quad$ Page

Figure S1. SEC-MALLS and Refractive Index (RI) traces of P(LiBNMB)-2.7

S3

Figure S2. SEC-MALLS and RI traces of P(LiBNMB)-3.3

Figure S3. SEC-MALLS and RI traces of P(LiBNMB)-9.9

Figure S4. SEC-MALLS and RI traces of P(LiBNMB)-24

Figure S5. SEC-MALLS and RI traces of $\mathrm{P}(\mathrm{LiBNMB})-55$

Figure S6. Representative ${ }^{13} \mathrm{C}$ NMR spectrum of $\mathrm{P}(\mathrm{LiBNMB})-55$

Coulommetric Calculation of mol\% Borate Degradation in CV Studies

Table S1. DOSY parameters for LiTFSI, LiBNMB, and P(LiBNMB) samples $\quad$ S10

Figure S7. DOSY ${ }^{1} \mathrm{H}$ NMR of $\mathrm{P}(\mathrm{LiBNMB})-55$ in propylene carbonate $\quad \mathrm{S} 11$

Figure S8. Fit of ${ }^{7}$ Li DOSY NMR of P(LiBNMB)-55 $\quad$ S12

Figure S9. Fit of ${ }^{1} \mathrm{H}$ DOSY NMR of P(LiBNMB)-55 S13

Table S2: Diffusivities, lithium transference number, and conductivities of LiTFSI, $\quad$ S14

LiBNMB, and P(LiBNMB) samples from DOSY NMR and EIS

Figure S10. The inverse Haven ratio $\beta$ versus $M_{n}$ for $\mathrm{P}(\mathrm{LiBNMB})$ samples $\quad \mathrm{S} 15$

Figure S11. Current decay profile for potentiostatic polarization experiments with $\quad$ S16 LiTFSI in PC

Figure S12. Nyquist plots for potentiostatic polarization experiments with

LiTFSI in PC

Figure S13. Current decay profile for potentiostatic polarization experiments with 
Figure S14. Nyquist plots for potentiostatic polarization experiments with

LiBNMB in PC

Figure S15. Current decay profile for potentiostatic polarization experiments with $\mathrm{P}(\mathrm{LiBNMB})-2.7$ in $\mathrm{PC}$

Figure S16. Nyquist plots for potentiostatic polarization experiments with $\mathrm{P}(\mathrm{LiBNMB})-2.7$ in $\mathrm{PC}$

Figure S17. Current decay profile for potentiostatic polarization experiments with $\mathrm{P}(\mathrm{LiBNMB})-9.9$ in $\mathrm{PC}$

Figure S18. Nyquist plots for potentiostatic polarization experiments with

$$
\mathrm{P}(\mathrm{LiBNMB})-9.9 \text { in } \mathrm{PC}
$$

Table S3. Potentiostatic polarization current and resistance values for LiTFSI, LiBNMB

P(LiBNMB)-2.7, and P(LiBNMB)-9.9 


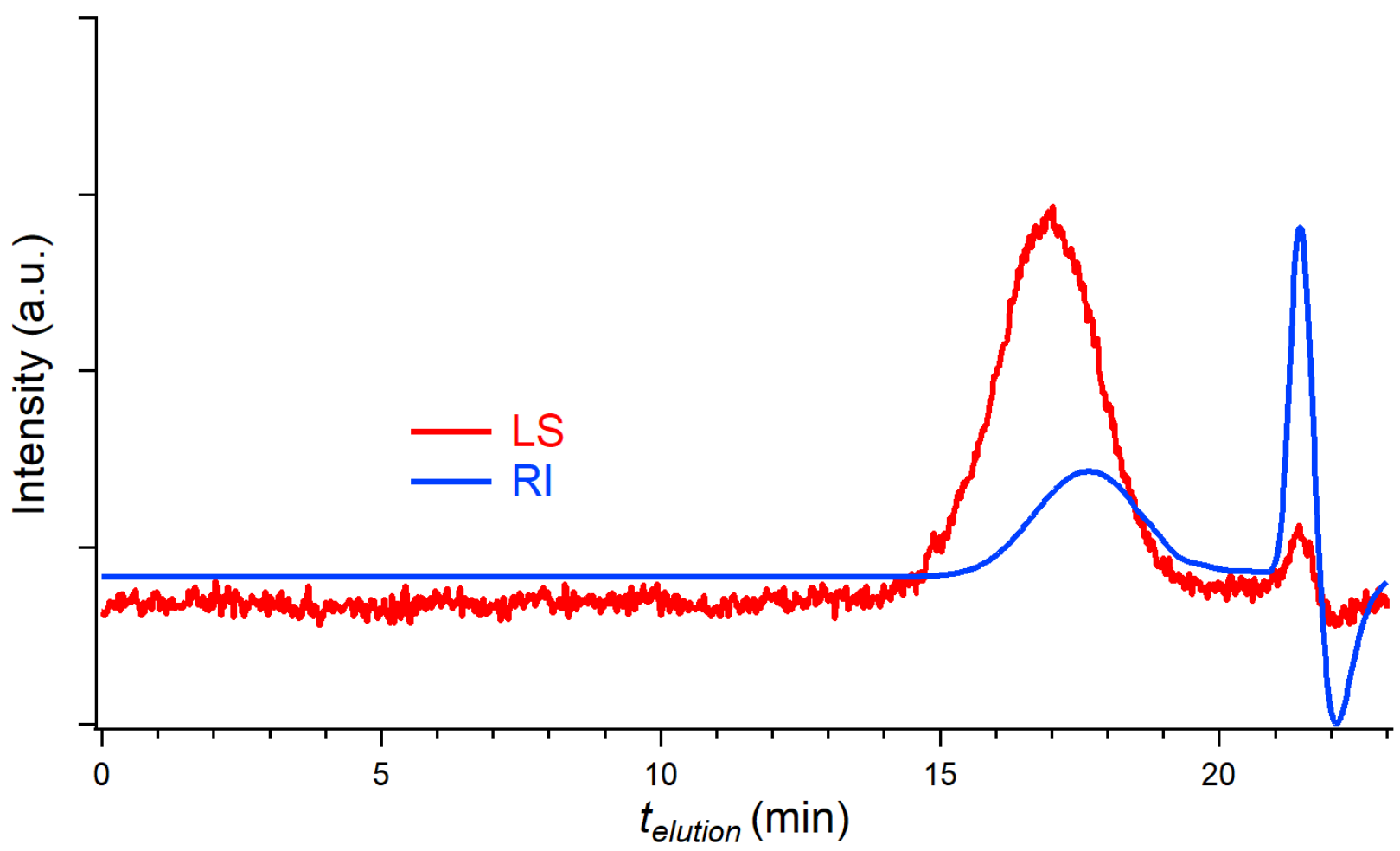

Figure S1. SEC-MALLS (red) and RI (blue) traces of P(LiBNMB)-2.7 with $50 \mathrm{mM} \mathrm{LiBr}$ DMF as the eluent. 


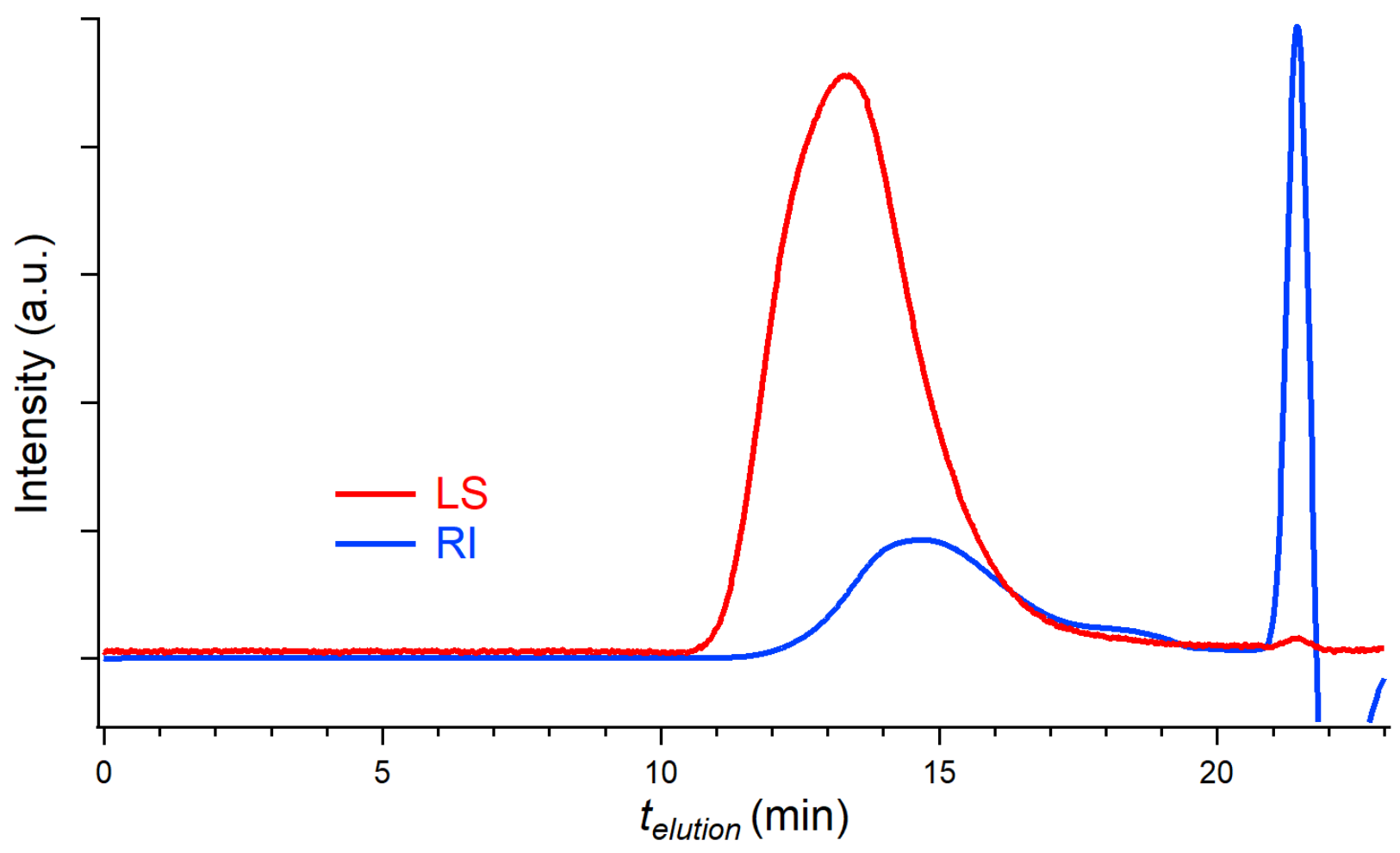

Figure S2. SEC-MALLS (red) and RI (blue) traces of P(LiBNMB)-3.3 with $50 \mathrm{mM} \mathrm{LiBr} \mathrm{DMF}$ as the eluent. 


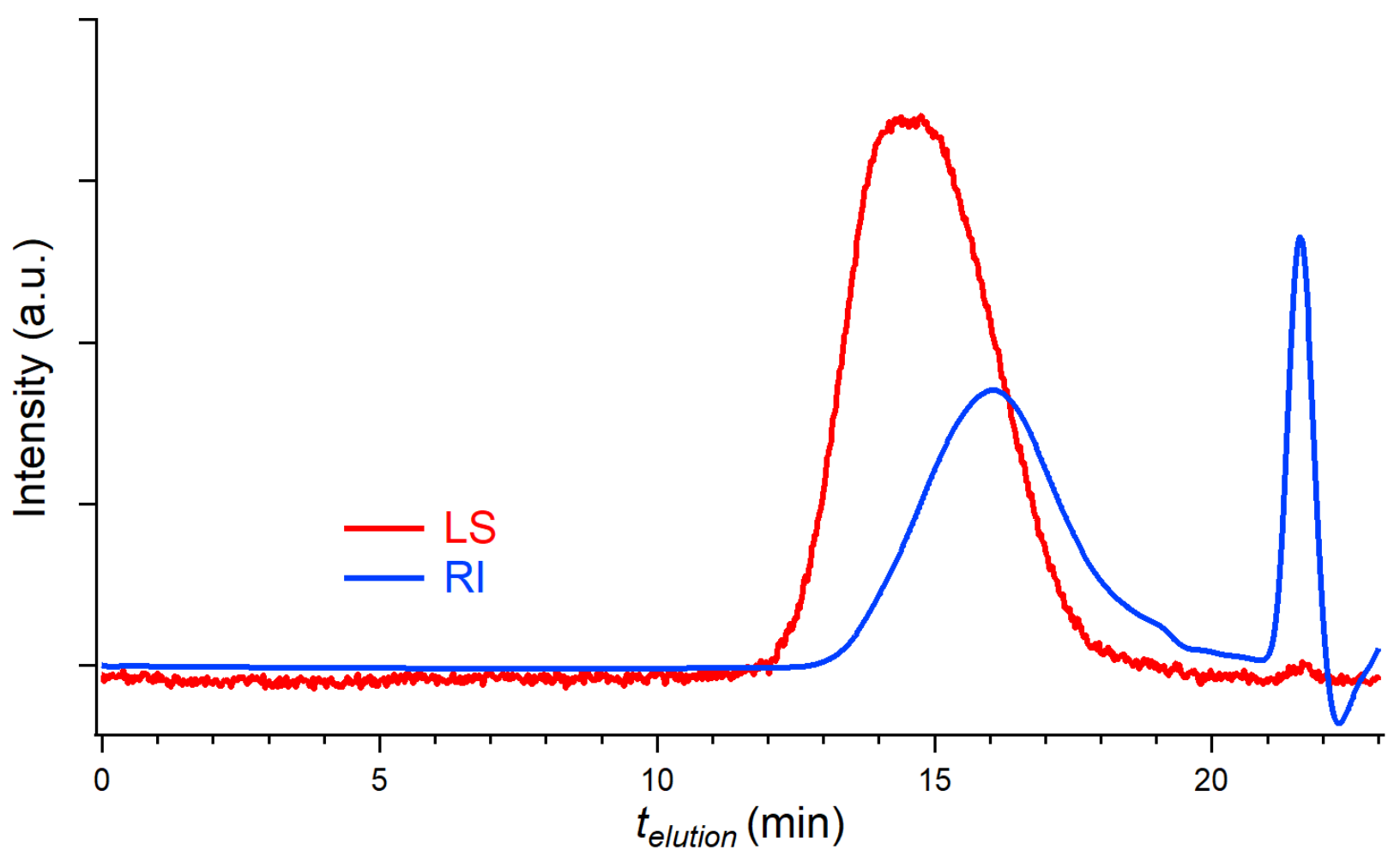

Figure S3. SEC-MALLS (red) and RI (blue) traces of P(LiBNMB)-9.9 with $50 \mathrm{mM} \mathrm{LiBr}$ DMF as the eluent. 


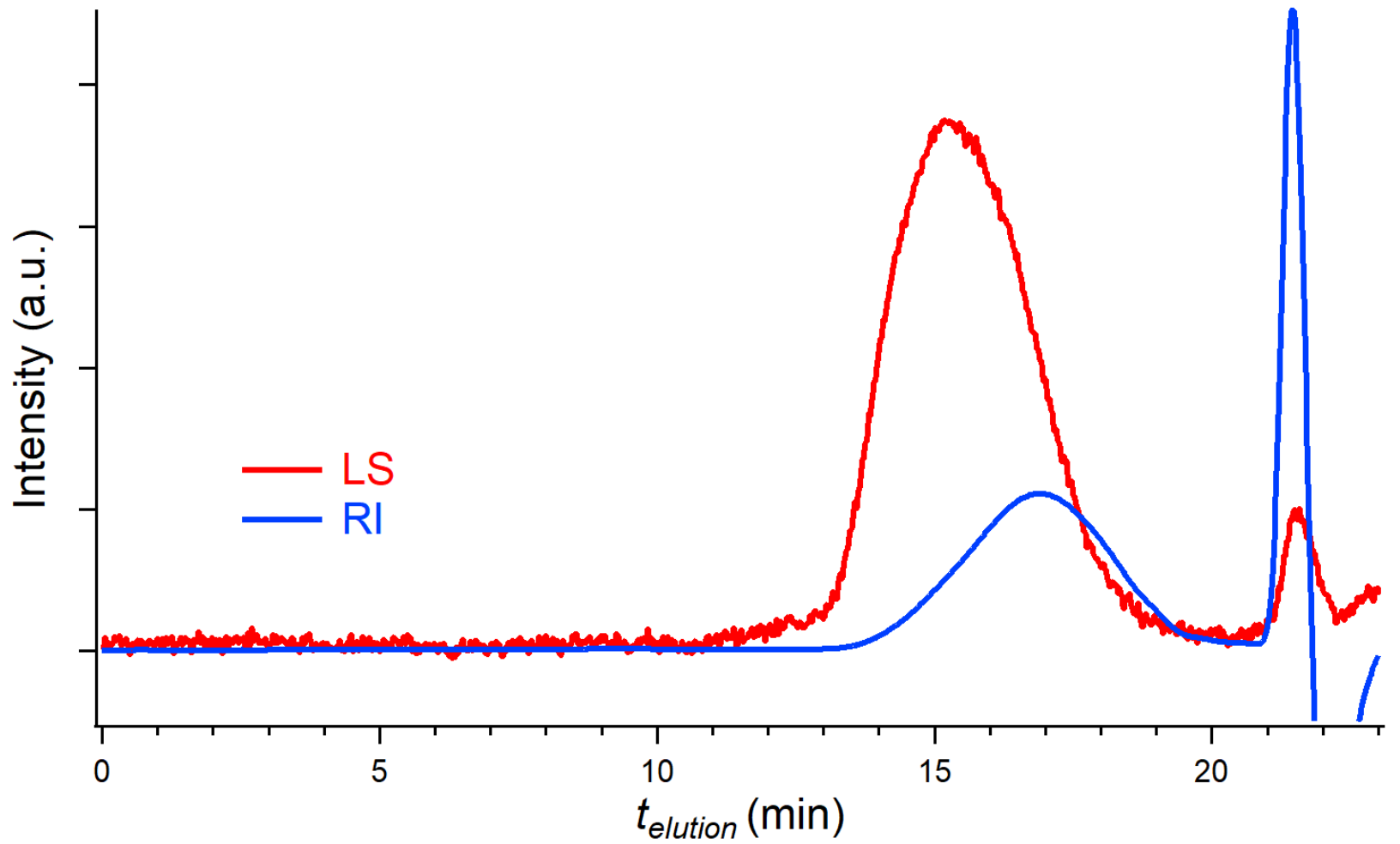

Figure S4. SEC-MALLS (red) and RI (blue) traces of P(LiBNMB)-24 with $50 \mathrm{mM} \mathrm{LiBr}$ DMF as the eluent. 


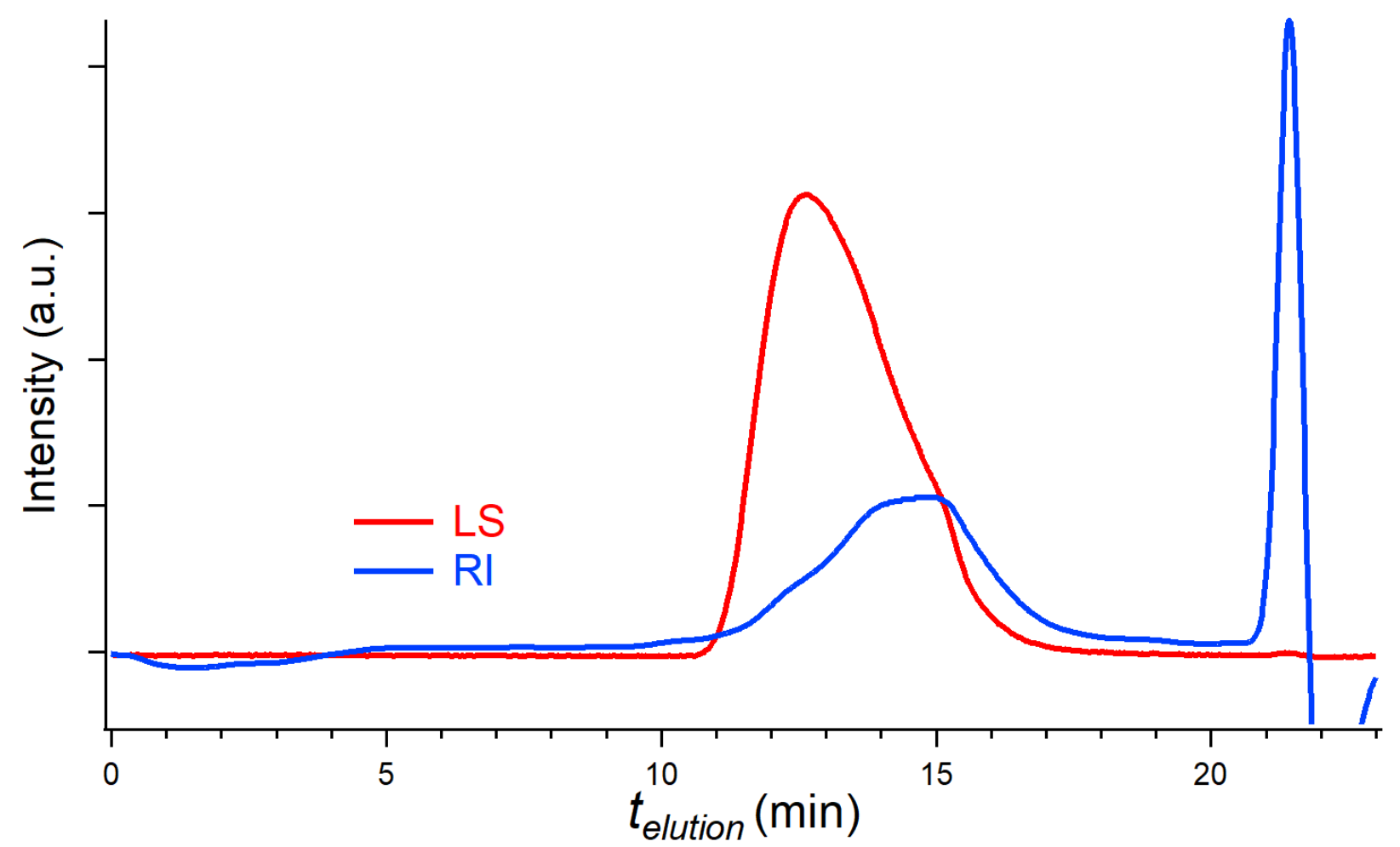

Figure S5. SEC-MALLS (red) and RI (blue) traces for P(LiBNMB)-55 with $50 \mathrm{mM} \mathrm{LiBr} \mathrm{DMF}$ as the eluent. 


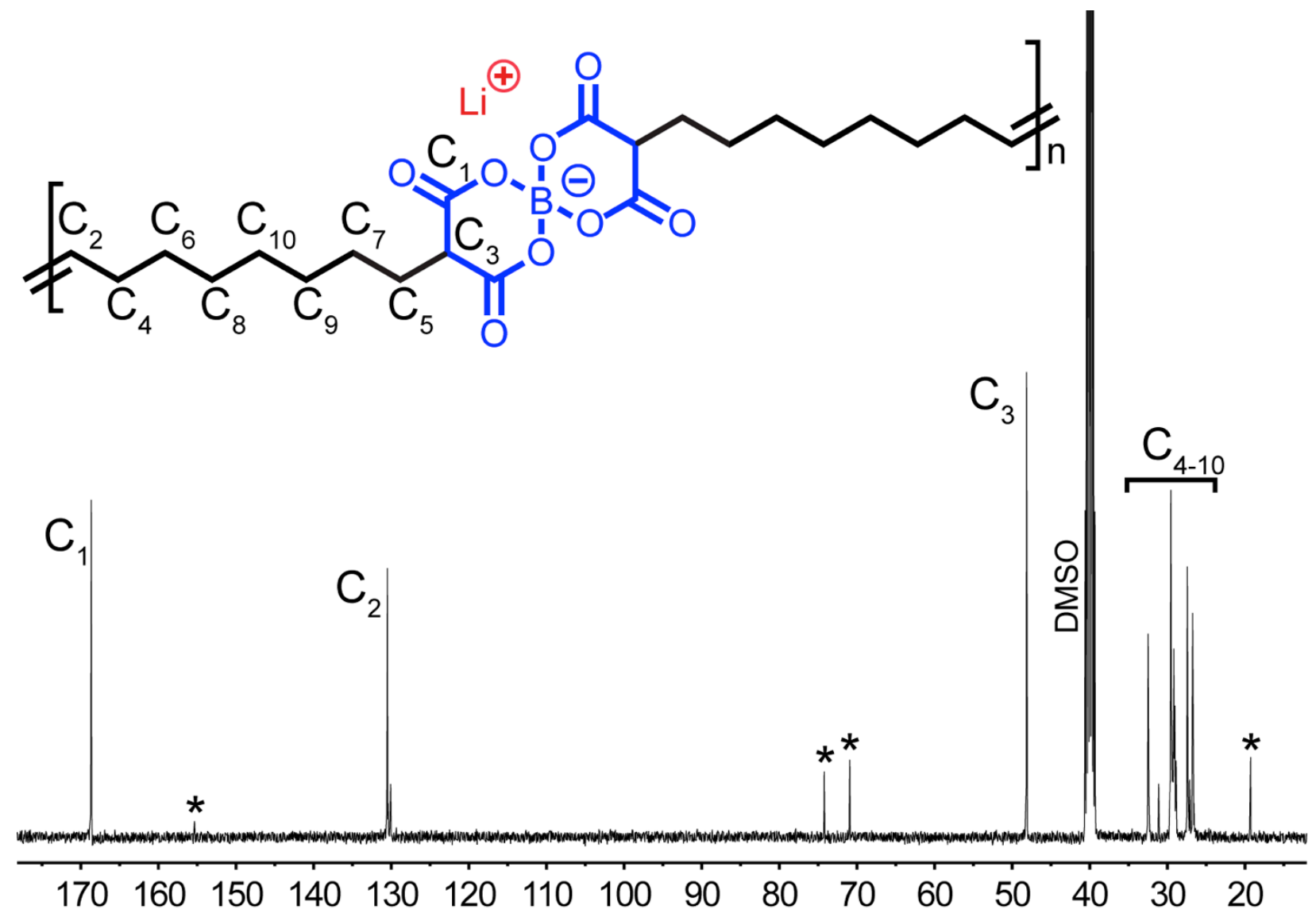

Figure S6. $100 \mathrm{MHz}{ }^{13} \mathrm{C}$ NMR of $\mathrm{P}(\mathrm{LiBNMB})-55$ in DMSO- $d_{6}$. A small amount of a propylene carbonate contaminant is indicated by the asterisks. 


\section{Coulommetric Calculation of mol\% Borate Degradation in CV Studies}

The mol\% of borate degradation observed over the first $40 \mathrm{CV}$ cycles of LiBNMB in PC and P(LiBNMB) in PC were determined using the Nernst equation:

$$
Q=i \Delta t=n F e
$$

where $F$ is Faraday's constant, and $e$ is the moles of electrons, and the total charge $(Q)$ derives from the the integral under the CV curve, calculated by summing the current $(i)$ multiplied by time interval $(\Delta t)$ for each data point. In using this expression, we assumed a one electron process for borate degradation $(n=$ 1) so that the number of moles of electrons equals the number of moles of reacted borate groups. This value was converted to a mol\% by per the following equation:

$$
\text { Mol\% borate degration }=\frac{\text { Moles reacted borate groups }}{\text { Total moles of borate groups in solution }}
$$


Table S1. DOSY parameters for LiTFSI, LiBNMB, and P(LiBNMB)

\begin{tabular}{cccccc}
\hline Sample & $\Delta_{L i}{ }^{+}(\mathrm{ms})$ & $\delta_{L i}{ }^{+}(\mathrm{ms})$ & $\Delta_{A}{ }^{-}(\mathrm{ms})^{a}$ & $\delta_{A}{ }^{-}(\mathrm{ms})^{a}$ & $t(\mathrm{~ms})^{b}$ \\
\hline LiTFSI & 394.73 & 0.0035 & 106.60 & 0.0021 & 0.0002 \\
LiBNMB & 494.87 & 0.0034 & 116.60 & 0.0021 & 0.0002 \\
P(LiBNMB)-2.7 & 392.73 & 0.0050 & 395.40 & 0.0030 & 0.0002 \\
P(LiBNMB)-3.3 & 342.73 & 0.0050 & 395.13 & 0.0032 & 0.0002 \\
P(LiBNMB)-9.9 & 392.73 & 0.0050 & 992.73 & 0.0050 & 0.0002 \\
P(LiBNMB)-24 & 142.73 & 0.0050 & 994.07 & 0.0040 & 0.0002 \\
P(LiBNMB)-55 & 493.00 & 0.0048 & 1993.0 & 0.0050 & 0.0002
\end{tabular}

${ }^{a}$ For LiTFSI, the anion analsysis relied on ${ }^{19} \mathrm{~F}$ NMR. For LiBNMB and P(LiBNMB), anion measurements were made using ${ }^{1} \mathrm{H}$ NMR.

${ }^{b}$ The same $t$ value was used for both $\mathrm{Li}^{+}$and the anion $\left(A^{-}\right)$. 


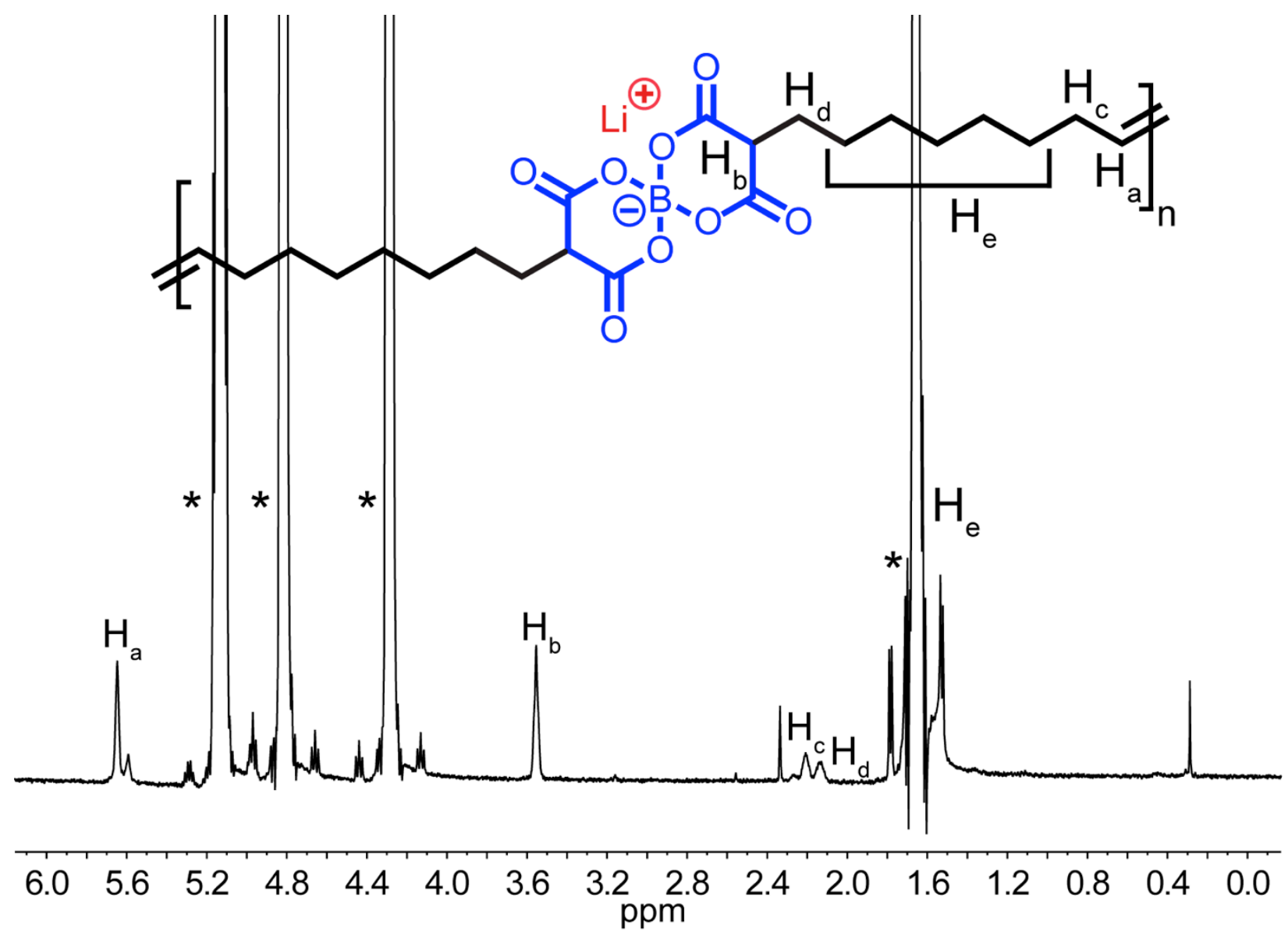

Figure S7. $500 \mathrm{MHz}{ }^{1} \mathrm{H}$ NMR spectrum of $\mathrm{P}(\mathrm{LiBNMB})-55$ in protiated propylene carbonate. This spectrum was selected from the DOSY NMR experiment at a gradient strength of $6.099 \mathrm{G} / \mathrm{cm}$. The protiated propylene carbonate solvent peaks are indicated by asterisks. 


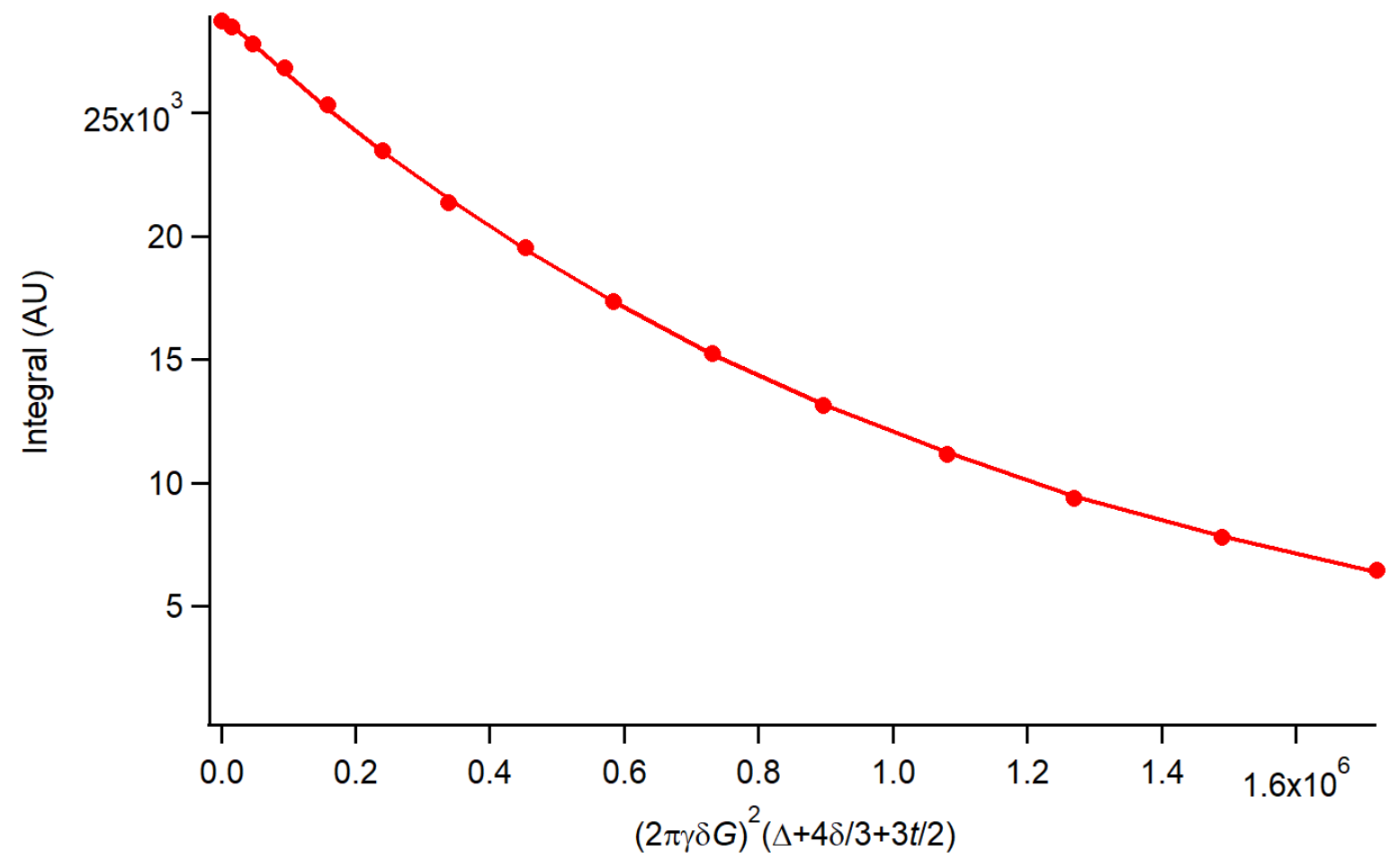

Figure S8. The integral of ${ }^{7} \mathrm{Li}$ NMR signal in DOSY NMR analysis of P(LiBNMB)-55 (see Page S4 and Table 1 for details). The red line is a simple exponential fit having $X^{2}=7.9$. 


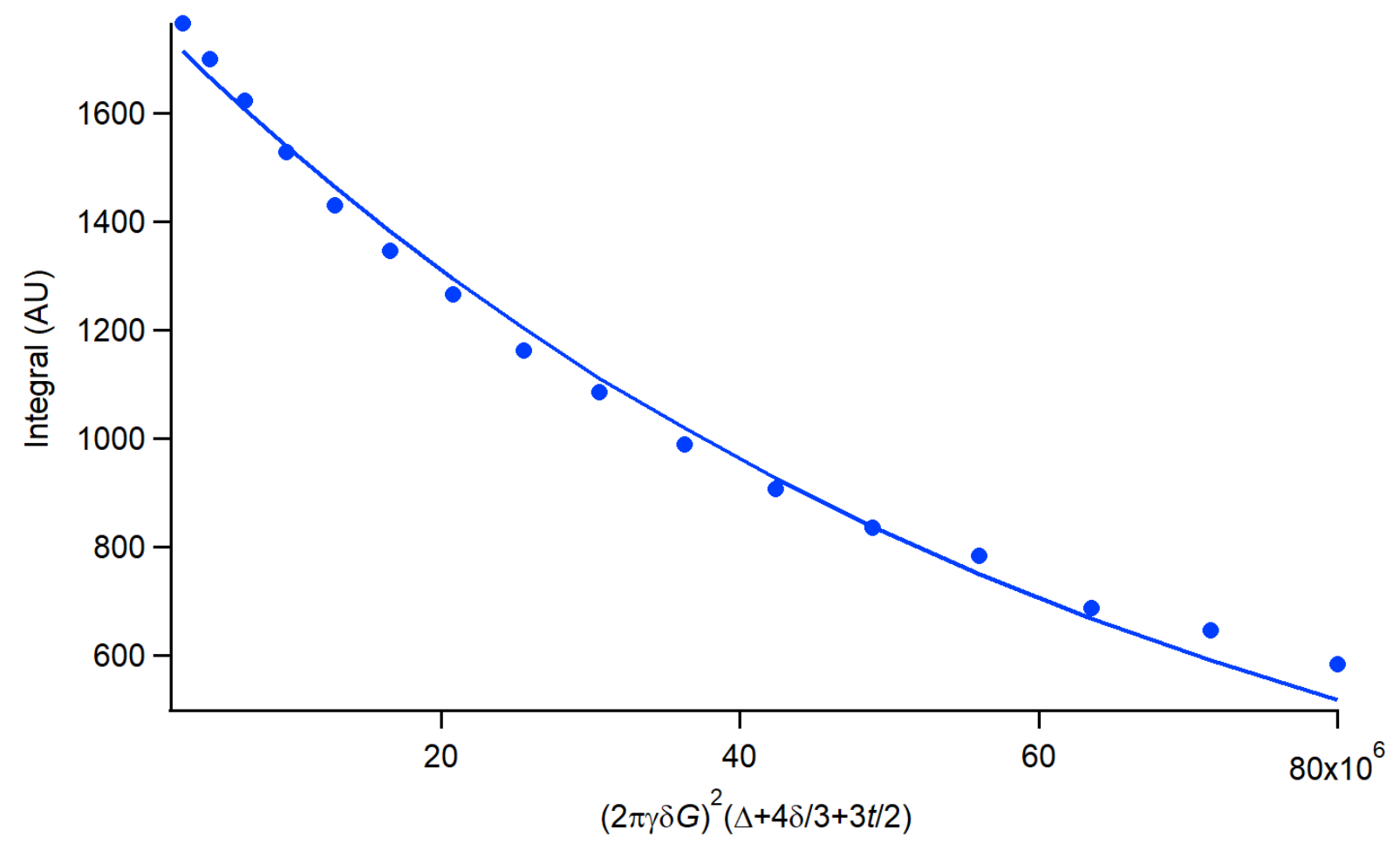

Figure S9. The integral of ${ }^{1} \mathrm{H}$ NMR as a function of various constants in DOSY NMR analysis for $\mathrm{P}(\mathrm{LiBNMB})-55$ (see Page S4 and Table 1 for details). The signal for the $\alpha-\mathrm{H}$ (labeled $\mathrm{H}_{\mathrm{b}}$ in main text Figure $1 b$ ) was integrated in this analysis. A simple exponential fit is shown, with $X^{2}=24.1$. 
Table S2. Ion diffusivities, lithium transference number, and conductivities of LiTFSI, LiBNMB, and P(LiBNMB) samples.

\begin{tabular}{ccccccc}
\hline & \multicolumn{3}{c}{ DOSY $^{a}$} & & EIS \\
\cline { 2 - 5 } Sample & $\begin{array}{c}D_{\mathrm{Li}}^{+} \\
\cdot 10^{7}\left(\mathrm{~cm}^{2} / \mathrm{s}\right)\end{array}$ & $\begin{array}{c}D_{\mathrm{A}}^{-} \\
\cdot 10^{7}\left(\mathrm{~cm}^{2} / \mathrm{s}\right)\end{array}$ & $t_{\mathrm{Li}}{ }^{+}$ & $\begin{array}{c}\sigma_{\text {Li }}{ }^{+} \\
(\mathrm{mS} / \mathrm{cm})\end{array}$ & $\begin{array}{c}\sigma_{\text {Total }} \\
(\mathrm{mS} / \mathrm{cm})\end{array}$ & $\begin{array}{c}\sigma_{\text {Total }} \\
(\mathrm{mS} / \mathrm{cm})\end{array}$ \\
\hline LiTFSI & 17.9 & 29.8 & 0.38 & 0.600 & 1.60 & $1.24^{b}$ \\
LiBNMB & 14.2 & 12.0 & 0.54 & 0.479 & 0.883 & $0.469^{b}$ \\
P(LiBNMB)-2.7 & 10.3 & 3.13 & 0.77 & 0.363 & 0.473 & $0.367^{c}$ \\
P(LiBNMB)-3.3 & 9.66 & 1.90 & 0.84 & 0.342 & 0.409 & $0.387^{c}$ \\
P(LiBNMB)-24 & 8.01 & 0.981 & 0.91 & 0.331 & 0.364 & $0.336^{c}$ \\
P(LiBNMB)-55 & 8.79 & 0.555 & 0.94 & 0.276 & 0.295 & $0.311^{c}$ \\
\end{tabular}

${ }^{a}$ Measured at $300 \mathrm{~K}$ and $\left[\mathrm{Li}^{+}\right]=0.092 \pm 0.003 \mathrm{M}$ in propylene carbonate

${ }^{b}$ Measured at $295 \mathrm{~K}$ and $\left[\mathrm{Li}^{+}\right]=0.100 \pm 0.001 \mathrm{M}$ in propylene carbonate

${ }^{c}$ Measured at $295 \mathrm{~K}$ and $\left[\mathrm{Li}^{+}\right]=0.092 \pm 0.003 \mathrm{M}$ in propylene carbonate 


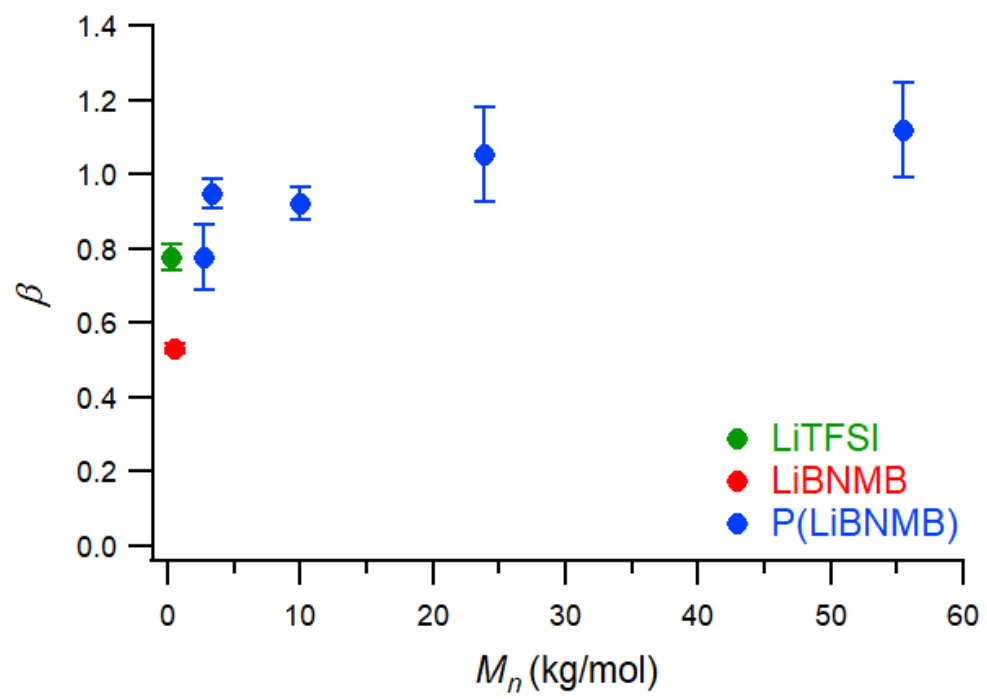

Figure S10. The inverse Haven ratio $\beta=\sigma_{\text {Total,EIS }} / \sigma_{\text {Total,NMR }}$ for LiTFSI, LiBNMB and P(LiBNMB) as a function of molecular weight. For all DOSY measurements, $\left[\mathrm{Li}^{+}\right]=0.092 \pm 0.003 \mathrm{M}$. For the EIS measurements, $\left[\mathrm{Li}^{+}\right]=0.092 \pm 0.003 \mathrm{M}$ for $\mathrm{P}(\mathrm{LiBNMB})$, whereas $\left[\mathrm{Li}^{+}\right]=0.100 \pm 0.001 \mathrm{M}$ for LiTFSI and LiBNMB. 


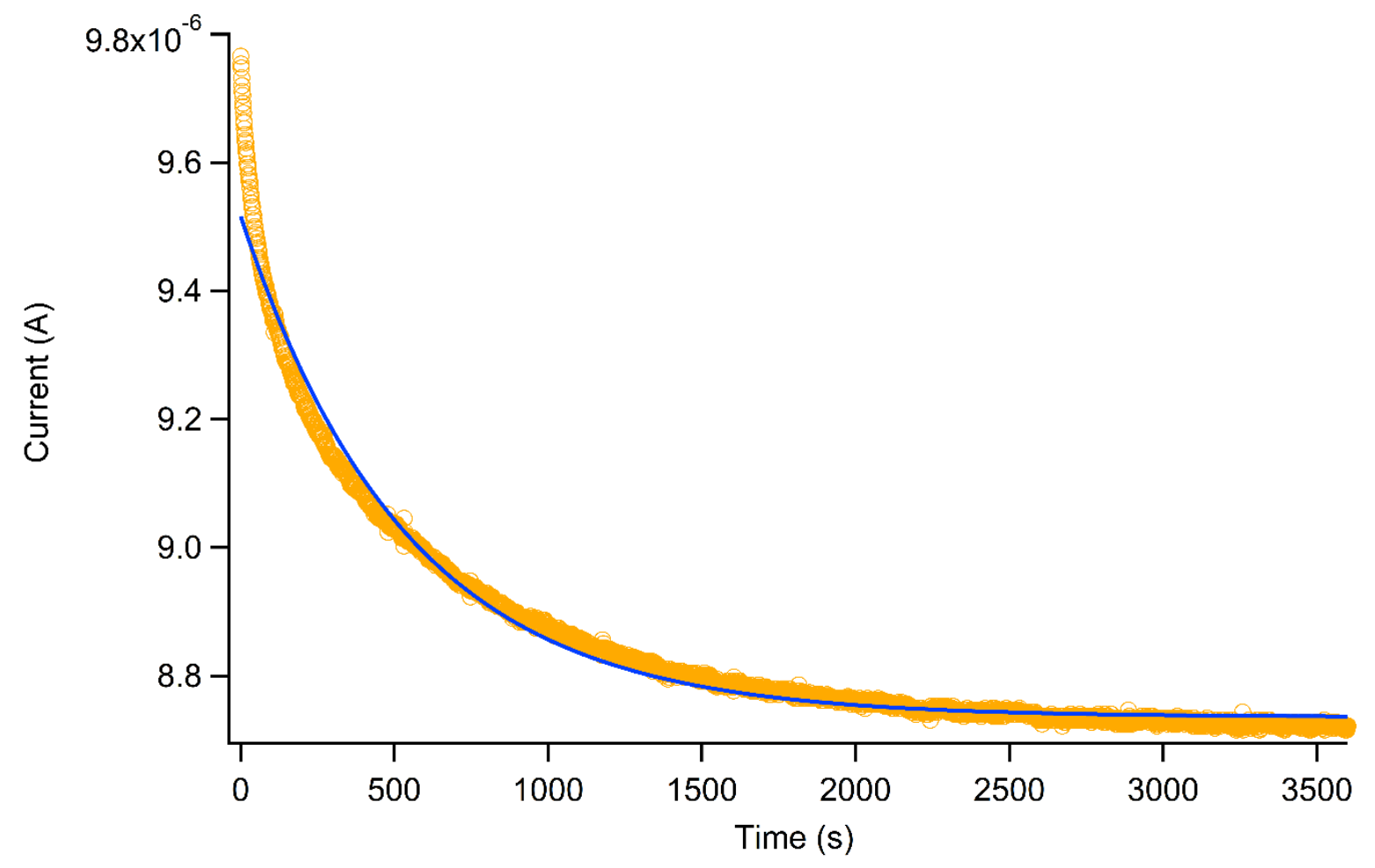

Figure S11. Current decay profile for [LiTFSI] $=0.09 \mathrm{M}$ in PC under an applied DC voltage of $10 \mathrm{mV}(v$. OCP). A simple exponential fit is shown, with $\chi^{2}=1.7 \times 10^{-12}$. 


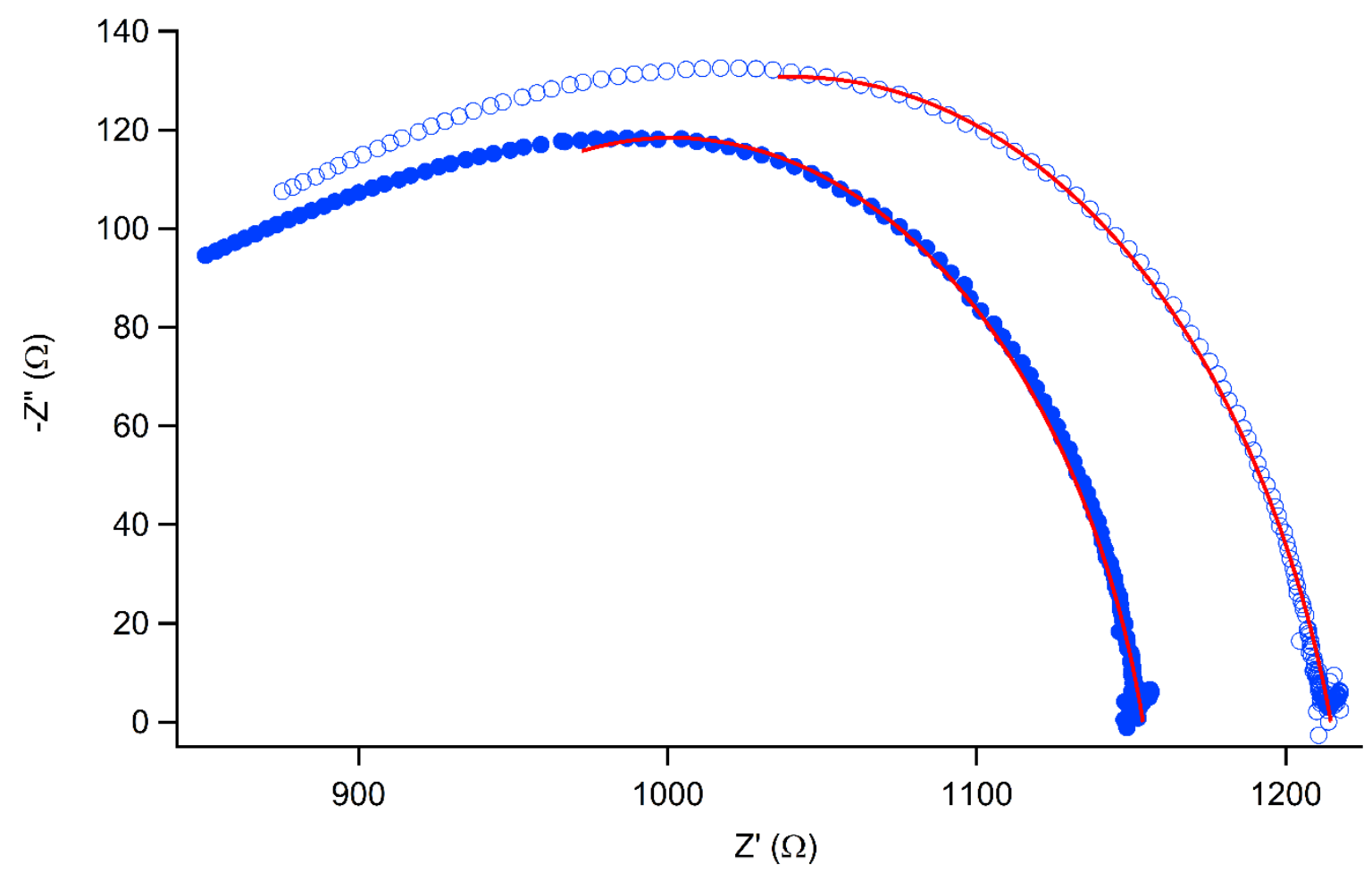

Figure S12. Nyquist plots for [LiTFSI] $=0.090 \mathrm{M}$ in PC fit to a $R_{1}\left(R_{2} Q\right)$ equivalent circuit, using data from from the maximum of each curve through the low frequency region. Closed circles represent EIS data measured prior to applying a DC voltage used to obtain $R_{0}$, open circles represent EIS data measured after the potentiostatic hold (see Figure S10) concluded from which $R_{s s}$ is obtained. The red lines represent the $R_{1}\left(R_{2} Q\right)$ fits before and after the potentiostatic hold experiment. 


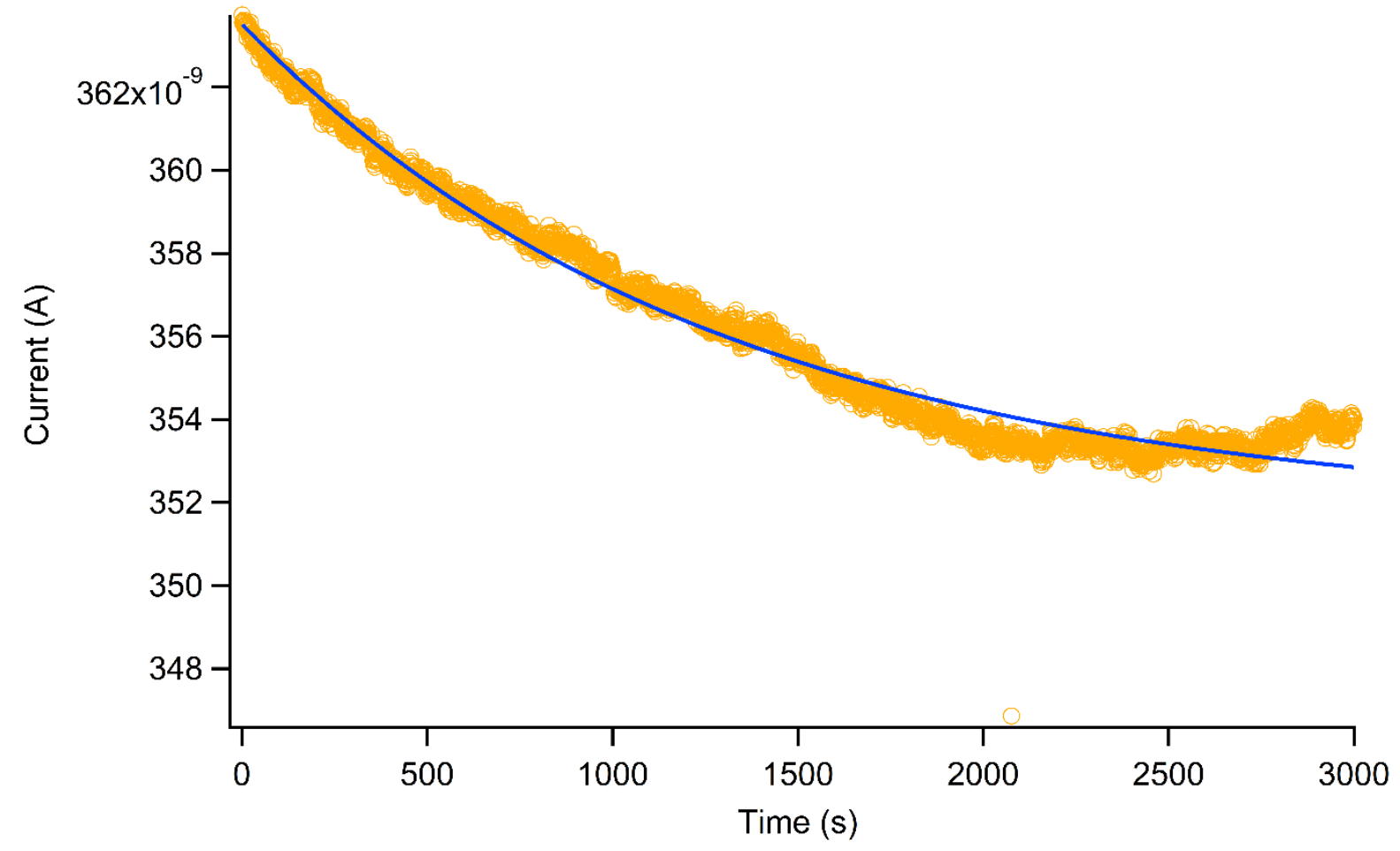

Figure S13. Current decay profile for $[\mathrm{LiBNMB}]=0.09 \mathrm{M}$ in PC under an applied DC voltage of $10 \mathrm{mV}\left(v\right.$. OCP). A simple exponential fit is shown, with $\chi^{2}=5.7 \times 10^{-16}$. 


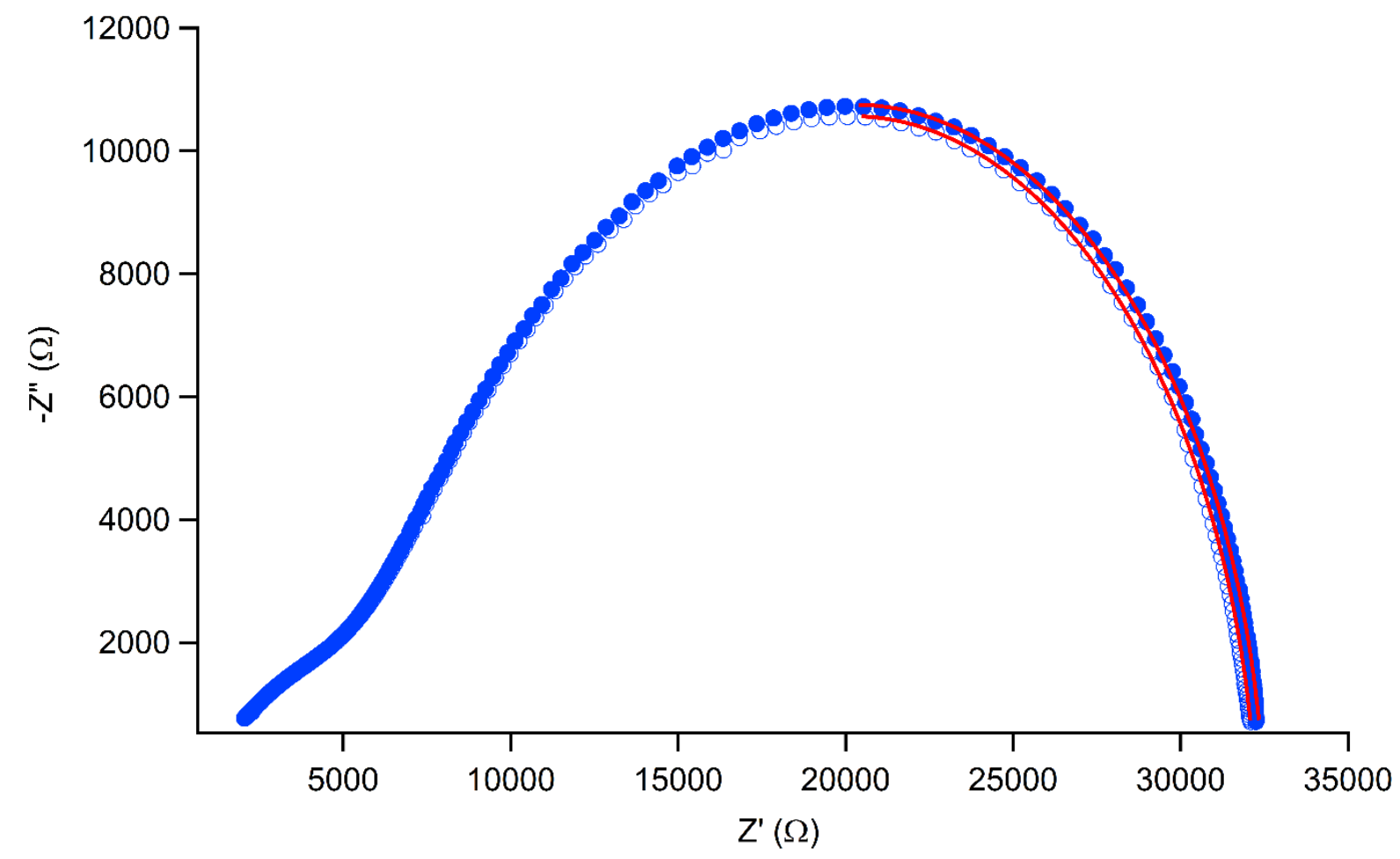

Figure S14. Nyquist plots for $[\mathrm{LiBNMB}]=0.090 \mathrm{M}$ in PC fit to a $R_{1}\left(R_{2} Q\right)$ equivalent circuit, using data from from the maximum of each curve through the low frequency region. Closed circles represent EIS data measured prior to applying a DC voltage used to obtain $R_{0}$, open circles represent EIS data measured after the potentiostatic hold (see Figure S12) concluded from which $R_{s s}$ is obtained. The red lines represent the $R_{1}\left(R_{2} Q\right)$ fits before and after the potentiostatic hold experiment. 


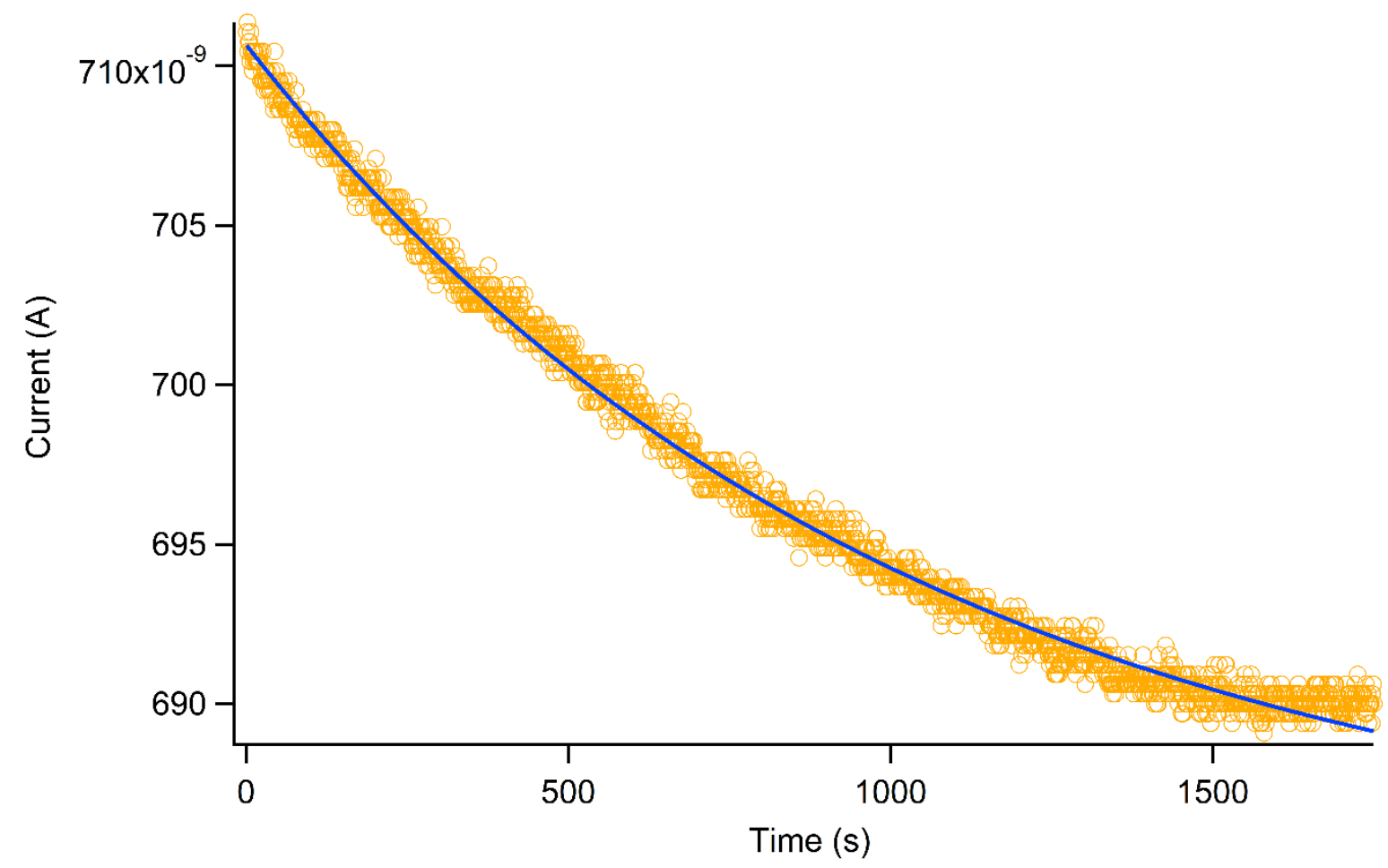

Figure S15. Current decay profile for $[\mathrm{P}(\mathrm{LiBNMB})-2.7]=0.094 \mathrm{M}$ in $\mathrm{PC}$ under an applied DC voltage of $10 \mathrm{mV}$ (v. OCP). A simple exponential fit is shown, with $\chi^{2}=3.7 \times 10^{-16}$. 


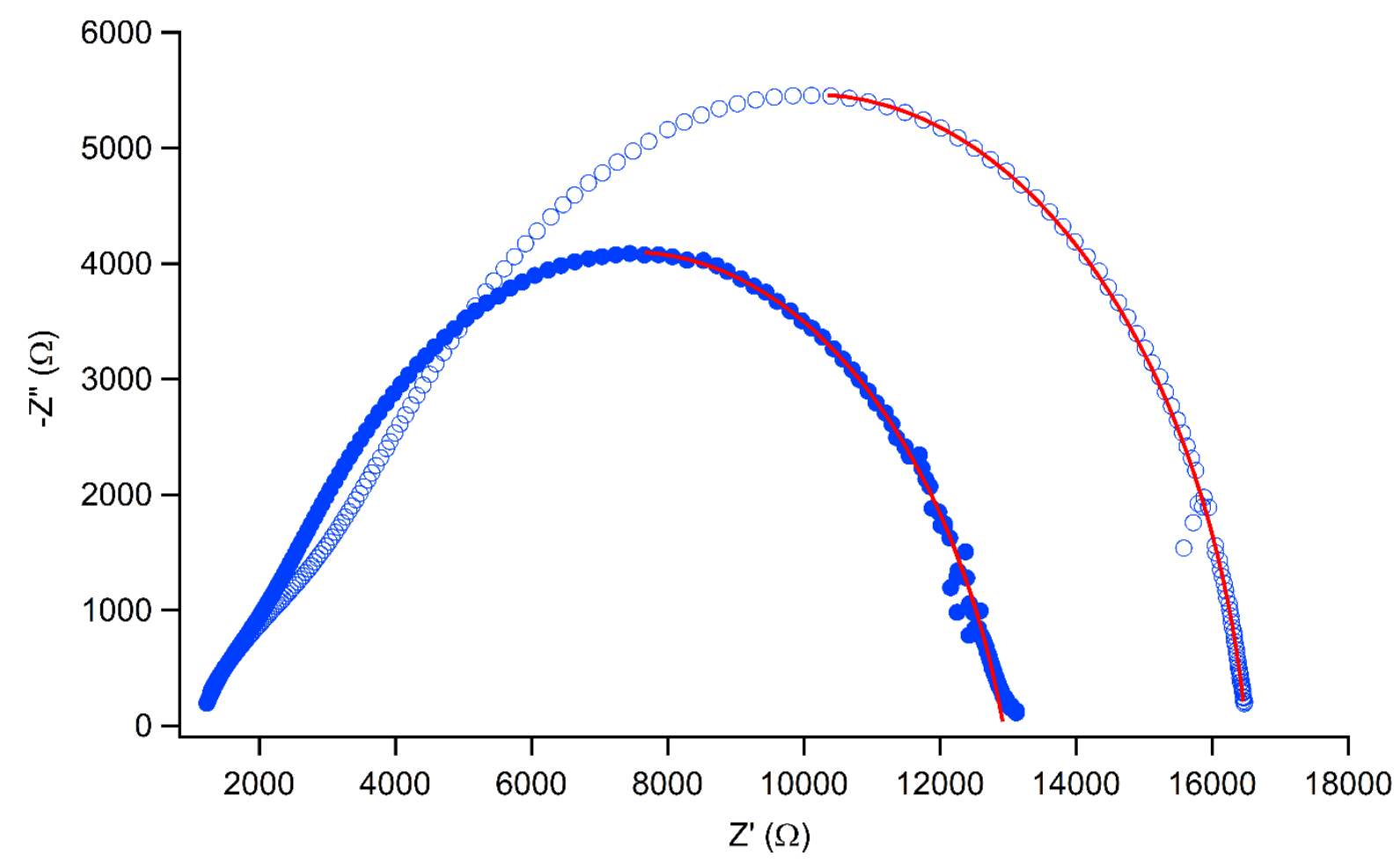

Figure S16. Nyquist plots for $[\mathrm{P}(\mathrm{LiBNMB})-2.7]=0.094 \mathrm{M}$ in $\mathrm{PC}$ fit to a $R_{1}\left(R_{2} Q\right)$ equivalent circuit, using data from from the maximum of each curve through the low frequency region. Closed circles represent EIS data measured prior to applying a DC voltage used to obtain $R_{0}$, open circles represent EIS data measured after the potentiostatic hold (see Figure S14) concluded from which $R_{s s}$ is obtained. The red lines represent the $R_{1}\left(R_{2} Q\right)$ fits before and after the potentiostatic hold experiment. In the fit used to obtain $R_{0}$, points from 11554 to $12429 \Omega$ in Z' were excluded from the fit due to noise evident in the data. 


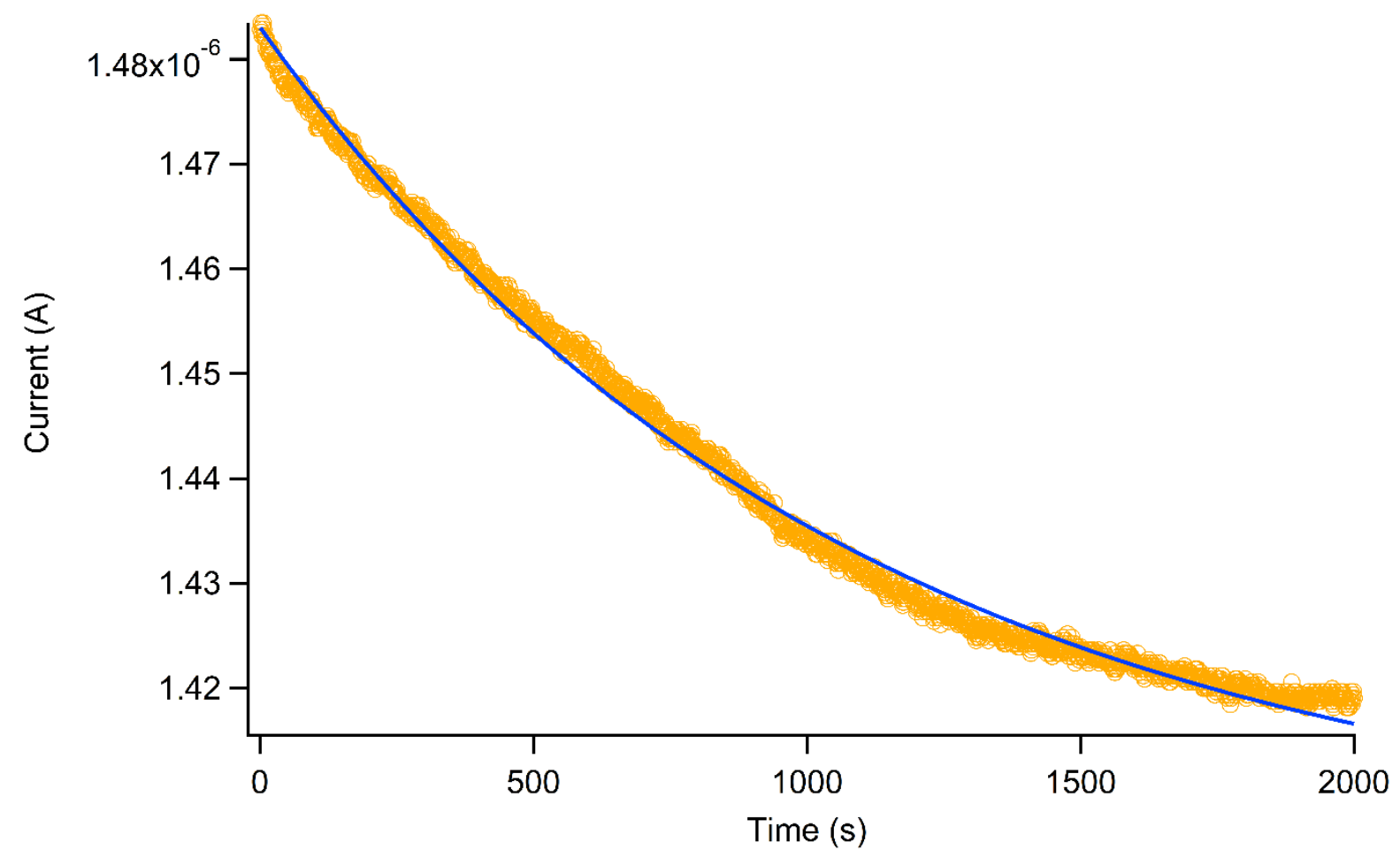

Figure S17. Current decay profile for $[\mathrm{P}(\mathrm{LiBNMB})-9.9]=0.090 \mathrm{M}$ in $\mathrm{PC}$ under an applied $\mathrm{DC}$ voltage of $10 \mathrm{mV}\left(v\right.$. OCP). A simple exponential fit is shown, with $\chi^{2}=3.4 \times 10^{-15}$. 


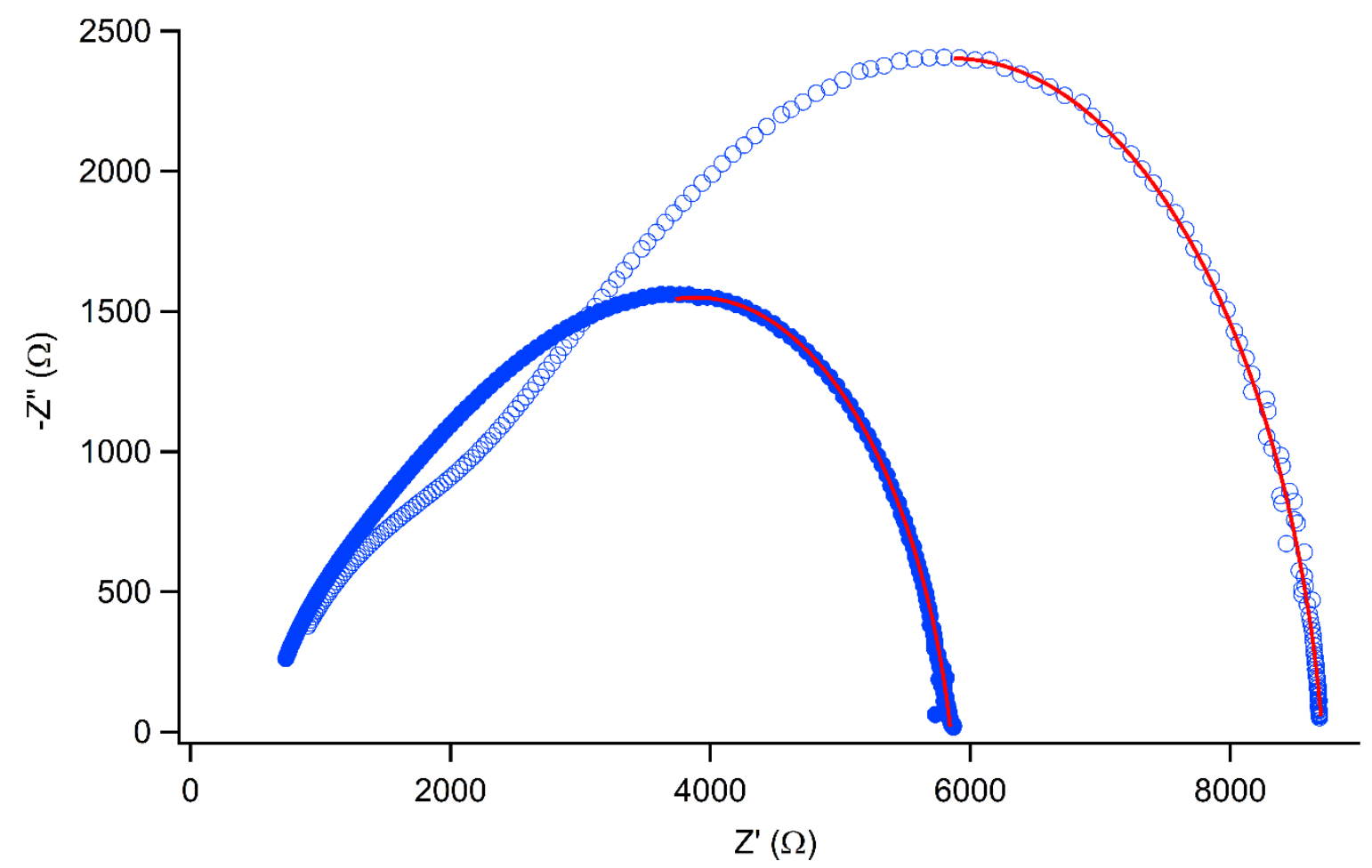

Figure S18. Nyquist plots for $[\mathrm{P}(\mathrm{LiBNMB})-9.9]=0.090 \mathrm{M}$ in $\mathrm{PC}$ fit to a $R_{1}\left(R_{2} Q\right)$ equivalent circuit, using data from from the maximum of each curve through the low frequency region. Closed circles represent EIS data measured prior to applying a DC voltage used to obtain $R_{0}$, open circles represent EIS data measured after the potentiostatic hold (see Figure S16) concluded from which $R_{s s}$ is obtained. The red lines represent the $R_{1}\left(R_{2} Q\right)$ fits before and after the potentiostatic hold experiment. 
Table S3. Potentiostatic Polarization Values for LiTFSI, LiBNMB, and P(LiBNMB)

\begin{tabular}{cccccc}
\hline Sample $^{a}$ & $R_{0}(\Omega)$ & $R_{S S}(\Omega)$ & $I_{0}(\mu \mathrm{A})$ & $I_{S S}(\mu \mathrm{A})$ & $t_{L i}{ }^{+}$ \\
\hline LiTFSI & 305 & 347 & 9.52 & 8.74 & 0.47 \\
LiBNMB & 24344 & 24304 & 0.364 & 0.352 & 0.38 \\
P(LiBNMB)-2.7 & 10986 & 12763 & 0.711 & 0.684 & 0.83 \\
P(LiBNMB)-9.9 & 3918 & 5689 & 1.48 & 1.40 & 0.98 \\
\hline
\end{tabular}

${ }^{a}$ Applied DC voltage $(\Delta V)$ for all samples was $10 \mathrm{mV} .\left[\mathrm{Li}^{+}\right]=0.09 \pm 0.004 \mathrm{M}$ for all samples (see Experimental Section for detailed conditions). 